STUDIA ROSSICA POSNANIENSIA, vol. XLI: 2016, pp. 401-410. ISSN 0081-6884.

Adam Mickiewicz University Press, Poznań

\title{
ПЕРЕВОДЧЕСКАЯ АКЦЕПТАЦИЯ И ПОЛЕМИКА В ИНТЕРПРЕТАЦИИ ЛИТЕРАТУРНЫХ ИМЕН СОБСТВЕННЫХ. НА ПРИМЕРЕ РУССКОГО И ПОЛЬСКОГО ПЕРЕВОДОВ САГИ О ГАРРИ ПОТТЕРЕ
}

\author{
TRANSLATIONAL ACCEPTANCE AND POLEMICS \\ IN THE INTERPRETATION OF LITERARY PROPER NAMES. \\ ON THE BASIS OF RUSSIAN AND POLISH TRANSLATIONS \\ OF THE HARRY POTTER SAGA
}

\author{
KONRAD RACHUT
}

\begin{abstract}
Translation of literary proper names boils down to either accurately rendering their original form/meaning or finding equivalents which have less in common with their original versions. In the article the author attempts to deduce what might have caused the translators to choose one of the two strategies by means of analysing chosen examples from the saga. Apparently, the translators' decisions stem not only from the limitations of respective languages and cultures, but also from their individual approach towards the original text.
\end{abstract}

Konrad Rachut, Uniwersytet im. Adama Mickiewicza w Poznaniu, Poznań - Polska, konrad.rachut@gmail.com

Невозможно представить себе работу переводчика без словарей. Они ведь нередко становятся опорой в процессе принятия переводческих решений и нахождения эквивалентов для слов из литературного текста-источника. Однако, несмотря на это, в словарях литературных имен собственных (ИС) помещается не разъяснение их семантики, а описание персонажей, называемых ими. Этот факт вытекает из того, что ИС вне контекста полноценным значением не обладают, так как

являясь знаком фиктивного существования описываемого в художественном произведении предмета, собственное имя получает свою полноценную значимость не только в контексте других знаков художественного произведения, но и в контексте, понимаемом как широчайший принцип ${ }^{1}$.

В связи с этим возможность установления семантики ИС читатель и переводчик получают только тогда, когда принимают во внимание со-

1 В.М. К а л и н к и н, Поэтика онима, Донецк 1999, с. 115. 
путствующий ИС пласт текста, что становится особо заметным в литературных произведениях. Как раз поэтому специфика семантики и, соответственно, перевода ИС имеет столько различий по сравнению с апеллятивами - у ИС невозможно установить постоянное значение, а только непосредственно связанное с контекстом литературного произведения.

Следует обратить внимание на то, что ономастами выделяются два основных типа ИС в художественных текстах: апеллятивизированные и неапеллятивизированные. В общих чертах, в случае обоих типов ИС, два базовых элемента семантического треугольника референт-слово-концепт с классической точки зрения являются проблематичными ${ }^{2}$. Во-первых, относительно уровня концепта, неапеллятивизированные ИС находят свое значение в самом тексте произведения - слова, написанные автором, наполняют ИС значением и становятся их дефиницией ${ }^{3}$. К примеру, английское имя Hedwig (являющееся эквивалентом польского имени Jadwiga), использованное Дж. К. Роулинг в саге о Гарри Поттере для названия его совы-опекунши, относится к святой Ядвиге Силезской - польской покровительнице сирот ${ }^{4}$. Таким образом историческое значение имени святой эксплицитно активизируется, поскольку Гарри действительно был сиротой, а сова выполняла роль его друга, помощника и защитника. Апеллятивизированные ИС, в свою очередь, наделяются семантикой благодаря тому, что их основой являются апеллятивы. Такие ИС - это „говорящие” ИС в прямом смысле слова: словарное значение составных частей ИС выражается в литературном референте ИС. К примеру, Раскольников становится бунтовщиком, Обломов - лентяем, а Разумихин - логически мыслящим человеком. В такой ситуации текст произведения становится лишь подтверждением причин, для которых автор выбрал или создал ИС, содержащее конкретный апеллятивный корень. Во-вторых, реальный уровень референта и у того, и у другого типа литературных ИС естественно утрачивается, так как автор описывает мир, не существующий в действительности - референт становится условным ${ }^{5}$. Только умелое владение словом позволяет писателю создать иллюзию реальности его

${ }^{2}$ Y. B e r t i 11 s, Beyond identification. Proper names in children's literature, Turku 2003, c. 24.

3 Там же, с. 29.

${ }^{4} \mathrm{~A} . \mathrm{S} \mathrm{t}$ a $\mathrm{n} \mathrm{d}$ o w i c z, Chosen aspects of the Polish translation of J.K. Rowling's "Harry Potter and the Philosopher's Stone" by Andrzej Polkowski: Translating proper names, [в:] электронный ресурс: http://translationjournal.net/journal/49potter.htm (13.10.2015).

${ }^{5}$ В.М. К а л и н к и н, От митературной ономастики к поэтонимологии, „Логос ономастики" 2006, № 1, с. 83. 
фикциональной действительности - в таком случае связь между словом и его референтом кажется читателям настоящей.

Отметим, что значение неапеллятивизированных ИС по своей натуре существенно отличается от значения апеллятивов - на первый план выдвигаются коннотации, которыми ИС сопровождаются. Точнее говоря, коннотации относятся не к самому ИС, а к его референту. Например, если ИС исторического персонажа используется автором для названия героя его романа, то делает он это с целью наделения фикционального референта ИС в произведении ассоциациями, связанными с реально существующим человеком. Следовательно, положения относительно того, что ИС коннотируют, являются лишь упрощением. По сути, коннотации заложены в первичном референте данного ИС, а не в самом ИС. Используя коннотации первичного референта ИС, писатель создает параллель между историческим персонажем и героем своего произведения, которая основана на сходствах между обоими лицами. Эти сходства активизируют знания читателя и, соответственно, вызывают ассоциацию. Безусловно, для осознания этого факта читателю необходимы определенные энциклопедические знания, что в действительности часто не имеет места.

Независимо от типа ИС, подбирая их для определенного элемента действительности своего произведения, писатель использует антономазию ${ }^{6}$. Суть этого явления заключается в том, что значение производного слова либо коннотации первичного референта ИС, бытующего вне мира произведения, актуализируются в контексте конкретных черт носителя ИС в произведении. Иначе говоря, контекстуальное значение ИС выявляется с помощью основного ${ }^{7}$. Благодаря ИС и сопровождающим его описаниям в тексте автор подсказывает читателю, на какие языковые или культурные факты он в данном ИС ссылается. Таким образом, ИС становится лишь верхушкой имплицитного айсберга семантики - настолько сжатый графический знак обладает обширным контекстуальным смыслом.

В связи с этим базовая функция идентификации референта ИС уходит на задний план - ИС наделяется функцией характеристики, словно являясь метафорой $\bar{\nu}^{8}$ По сути, ИС можно в такой ситуации воспринимать как краткий пересказ всего того, что было сказано на тему данного референта на протяжении всего произведения. Писатель

${ }^{6}$ С.Ю. К а п к о в а, Перевод иччных имен и реалий в произведении Дж.К. Ролинг „Гарри Поттер и Тайная комната", „Вестник ВГУ. Сер. Лингвистика и межкультурная коммуникация" 2004, № 1, с. 76.

7 Н.В. 3 и м о в е ц, К вопросу о значении и переводе имени „Гарри Поттер” в романах Дж. К. Роулинг, „Вестник МГОУ. Сер. Лингвистика” 2011, № 5, с. 87.

8 М.В. Н и к и т и н, Лексическое значение слова, Москва 1983, с. 39. 
заранее разрабатывает сюжет всей книги и на его основании называет конкретный элемент фикциональной действительности. „Он знает характеры, занятия душевные и физические занятия персонажей" ${ }^{\prime \prime}$, а эта информация, естественно, недоступна для читателя. Поэтому читатель обязан обратить внимание на все информационные нюансы, относящиеся к референту ИС, поскольку только благодаря экспликации вышеприведенных фактов он сможет максимально приблизиться к первоначальному авторскому замыслу со своей интерпретацией. Конечно же, самой выгодной была бы та ситуация, когда сам автор произведения объяснил бы, что привело его к использованию конкретного ИС по отношению к данному референту. Такую возможность читатели, переводчики и литературоведы получают, однако, крайне редко, что заставляет их дедуцировать.

Переводчик, поняв оригинальный замысел писателя с позиции читателя-интерпретатора, перевоплощается и начинает играть роль автора перевода. Надо подчеркнуть, что создание качественного перевода ИС является огромным культурно-языковым вызовом, так как все ИС, в особенности неапеллятивизированные, глубоко укоренились в культурном пространстве, к которому принадлежит автор, либо относятся к элементам третьей культуры. Из этого вытекает факт, что язык - это не единственная граница, которую переводчику приходится перешагнуть. Он должен также суметь либо передать существенные факты культуры, чтобы дать читателям возможность правильно понять ИС, либо подстроить языковой и культурный пласты ИС к переводящим языку и культуре. Несомненно, текст-источник направлен на совсем другую аудиторию, обладающую совсем иными языковыми и культурными знаниями, чем получатели перевода, так что без межкультурного посредничества здесь невозможно обойтись. Широко понимаемая переводческая полемика вытекает не только из субъективности интерпретации литературного произведения, но также из ограничений, навязываемых культурой и языком адресатов перевода. Чаще всего бывает так, что тот второй факт становится „узким местом” для ИС - не имея возможности воссоздать полное значение ИС, переводчик вынужден выбрать основное русло значения по своему усмотрению.

Получается, что переводчик в процессе перевода ИС обычно вынужден приближать автора текста-источника к получателям перевода. Это связано с тем, что между обеими культурами имеются настолько существенные расхождения, что выраженный в оригинальном ИС концепт приходится перестраивать, в конечном итоге заметно модифицируя ИС в переводе, что после сравнения с оригиналом понимаем как переводческую полемику. При этом такая тенденция наблюдается

${ }_{9}^{9}$ С.Ю. К а п к о в а, указ. соч., с. 76. 
в тех ситуациях, когда данный референт играет существенную роль в произведении и когда потенциальный перевод ИС способен в какой-то степени отразить значение оригинального ИС. Что касается переводческой акцептации, то она обычно выражается в том, что переводчик либо оставляет в переводе форму первоначального ИС, либо вводит незначительные изменения в суффиксальную структуру ИС, либо, наконец, переводит составляющие исходного ИС пословно. Независимо от того, намерен ли переводчик согласиться или поспорить с писателем, ему приходится осуществить такой же путь по ономазиологической тропе значений ${ }^{10}$. Исходя из концепта, заложенного в ИС, переводчик постепенно подбирает подходящие к нему слова. В дальнейшей части статьи представим примеры как переводческой полемики, так и акцептации в переводах ИС из саги о Гарри Поттере на русский и английский языки, пытаясь одновременно найти возможные причины, которые привели переводчиков к принятию таких решений. Подчеркнем, однако, что такие рассуждения имеют весьма субъективный характер и поэтому могут не быть единственными вариантами объяснения произошедших переводческих процессов.

Пример 1. Английский язык: Skele-Gro. Русский язык: Скелерост. Польский язык: Szkiele-Wzro.

Настоящие ИС называют медицинское средство, благодаря которому возможно полное восстановление костей в теле человека, причем это происходит мгновенно - в течение одной ночи. Данный медикамент был использован, когда Гарри во время игры в квидиш сломал себе руку, а один из его учителей случайно удалил из нее кости, вместо того чтобы привести к их сращиванию. Такие магические свойства и выражаются в ИС, называющем этот медикамент: корень skele отсылает к понятию скелета, a grow - к понятию роста ${ }^{11}$.

В случае обоих переводов имеем дело с точным отражением исходного смысла, но с использованием разных стратегий их записи. Русская переводчица Мария Спивак решила избавиться от исходного дефиса и срастить оба корня, что можно интерпретировать как интралингвальное отражение магических свойств медикамента. В свою очередь польский переводчик Анджей Польковский точнейшим образом передал как исходную семантику, так и исходную форму ИС. Соответственно, слова szkiele и wzro не только являются частями слов, где усечены конечные согласные (szkiele- $t$ и wzro-st, аналогично оригиналу - skele-ton и gro-w), но также соединены с помощью дефиса. Так поль-

${ }^{10} \mathrm{H}$. K a r d e 1 a, Onomazjologiczny aspekt semantyki kognitywnej, [в:] Jezyk a kultura. Podstawy metodologiczne semantyki wspótczesnej, pod red. I. Nowakowskiej-Kempnej, Wrocław 1992, c. 47.

11 С.Ю. К а п к о в а, указ. соч., с. 77. 
ский переводчик выражает свою полную акцептацию идеи писательницы, а русская переводчица полемизирует с оригиналом на уровне орфографии.

Пример 2. Английский язык: Bludger. Русский язык: Наnaдала. Польский язык: Ttuczek.

Оставаясь в теме игры квидиш (название которой может также показаться интересным), проанализируем название одного из „живых" мячей, используемых в игре. Их заданием было сбрасывание игроков с метел или наношение им травм, или же, по крайней мере, утруднение им полета. Писательница точно выразила заложенные в них коварные намерения, поскольку в ИС она относится к слову bludgeon 12 - 'сильно кого-то ударять при помощи тяжелого предмета'. Несомненно, Дж. К. Роулинг метко подчеркивает характер называемого ей мяча. Переводчики также воссоздают заложенную в этом ИС характеристику мяча, причем в обоих случаях наблюдаем прием конкретизации.

В переводе М. Спивак наблюдаем прием изменения семантической перспективы онима, ибо она подчеркивает в нем эмоциональную интерпретацию действий мяча - удар становится актом напасти. Следует отметить, что референт данного ИС наделяется человеческими качествами. Совсем противоположные ассоциации вызывает в читателе польский перевод. Связано это с тем, что существительное ttuczek в основном ассоциируется с молотком для отбивания мяса. По всей вероятности, А. Польковский хотел придать ИС комический оттенок, хотя глагол tłис лишен столь однозначной коннотации и имеет значение, аналогичное тому, которым обладает слово 'bludgeon'. Поэтому полагаем, что польский перевод в очередной раз оказался ближе акцептации по сравнению с русским, несмотря на то, что на этот раз А. Польковский также добавил к семантике ИС что-то свое.

Пример 3. Английский язык: Pensieve. Русский язык: дубльдум. Польский язык: myślodsiewnia.

Перейдем к ИС, которое называет чашу, используемую великими волшебниками для архивизации и упорядочения своих мыслей. В книгах о Гарри Поттере содержимое чаши, то есть человеческие мысли, представляется как жидкость и извлекается из головы при помощи волшебной палочки, которая прикладывается к виску. Таким образом можно избавиться от лишних мыслей и оставить их на потом. По словам Альбуса Думбльдора - директора школы Хогвартс, владельца чаши, - в свободное время можно к своим мыслям вернуться, просматривая их словно фильм и замечая детали, на которые раныше не

12 A. P o 1 k o w s k i, Kilka stów od ttumacza, czyli krótki poradnik dla dociekliwych, [в:] J.K. R o w 1 i n g, Harry Potter i Kamień Filozoficzny, Poznań 2000, c. 205. 
обратилось внимания. Исходное название чаши, Pensieve, Дж. К. Роулинг основывает на словах pensive и sieve ${ }^{13}$, причем они подобраны настолько умело, что их сращивание привело только лишь к добавлению $e$ к слову pensive. Первое слово переводится на русский язык как 'задумчивый, погруженный в раздумье' - существенно то, что это относится к серьезным мыслям. Второе слово, в свою очередь, обозначает сито. Следовательно, это ИС отчетливо „говорит” о том, что описываемый им объект предназначен для просеивания мыслей.

Что касается перевода М. Спивак, невозможно не заметить в нем корня дум, несомненно связывающего чашу с мыслями. Однако вместо того чтобы сохранить метафору сита, переводчица приняла решение о приближении предмета к его владельцу - дубль относится к фамилии Думбльдор. Воспринимаем это решение как компенсацию непередаваемого, на взгляд переводчицы, смысла сита, несмотря на тот факт, что дубльдум звучит несколько комически. Безусловно, в этом случае наблюдается прием апеллятивизации исходного ИС - в переводе оно записывается с маленькой буквы. Из этого вытекает то, что, по мнению М. Спивак, чаша переходит из разряда артефактов уникальных в разряд обычных предметов, а это существенно усугубляет изначальную исключительность предмета. Аналогично поступил А. Польковский в случае своего варианта перевода. Создав слово myślodsiewnia, он искусно совмещает мышление (myśl) с просеиванием (odsiewnia). Благодаря использованию такой стратегии он полностью воссоздает как значение составляющих частей английского ИС, так и авторский прием их сращивания. Это сводится к тому, что первая буква слова odsiewnia позволяет первому слову плавно перейти во второе. Обобщая, можно сказать, что оба переводчика соглашаются с Дж. К. Роулинг лишь в незначительной степени, существенно измененяя не только семантику, но также и тип используемого ими слова для перевода ИС.

Пример 4. Английский язык: Portkey. Русский язык: портшлюс. Польский язык: świstoklik.

Сейчас займемся очередным магическим предметом, который на этот раз был предназначен для телепортации волшебников. Надо подчеркнуть, что он всегда должен был бы быть незаметным для посторонних глаз. Способность мгновенно переносить людей в пространстве писательница передает благодаря корню port, связанному с телепортацией или транспортом ${ }^{14}$. Ссылку на ключ $(k e y)$ понимаем как метафору, поскольку с помощью этого объекта волшебник „открывал" перед собой возможность телепортации.

${ }^{13}$ A. P o 1 k o w s k i, Kilka stów od tłumacza, czyli krótki poradnik dla dociekliwych, [в:] J.K. R o w 1 i n g, Harry Potter i Czara Ognia, Poznań 2001, c. 467.

14 Там же, с. 468. 
В обоих переводах невозможно не заметить, что в очередной раз наблюдается в них прием апеллятивизации. По всей вероятности, переводчики хотели таким способом привнести в предмет характер обыденности. Что касается значения, М. Спивак сохраняет корень порт, но ключ компенсирует при помощи шлюса, толкуемого как 'у кавалеристов - сжимание седла коленями и ляжками как условие прочной посадки'15. Замечаем здесь метафорическое использование существительного, параллельное оригиналу, так как во время полета волшебники всегда ощущали сжимание их внутренних органов и должны были оставаться без движения. При этом шлюс может также восприниматься как звукоподражание, на что А. Польковский делает в своем переводе особый упор. Итак, как świst ('свист'), так и klik ('клик') являются в польском языке выражениями ономатопеической природы. Первое отражает тот звук, который образуется, когда один объект проносится мимо другого, а второе ассоциируется с внезапностью. Благодаря этому переводчик сумел выразить быстроту перемещения на двух уровнях, в добавление плавно соединяя оба слова при помощи интерфикса о. Обобщая, можно сказать, что русская переводчица наполовину согласилась с вариантом ИС в оригинале, воссоздавая значение первого составляющего и метафорическое употребление второго, а польский переводчик решил полемизировать с оригиналом, конкретизируя семантику подлинника благодаря сосредоточению внимания на основном качестве предмета.

Пример 5. Английский язык: Death Eaters. Русский язык: Упивающзиеся Смертью. Польский язык: śmierciożercy.

Death Eaters - это единственное среди анализируемых примеров ИС, относящееся к людям. Этим ИС называется группа слуг Волан-де-Морта, выполняющих его приказы - чаще всего они убивали людей, а также пытали их. Тот факт, что они были убийцами, передается в их ИС, поскольку в дословном переводе они были „Пожирателями Смерти" (это и есть альтернативная версия перевода ИС издательства Росмэн). Пожирание смерти несомненно ассоциируется с коварностью и беспощадностью действий этой группировки. М. Спивак отражает их столь зловещие качества с помощью слова упивающиеся, что еще сильнее подчеркивает их фанатизм. А. Польковский принял решение создать неологизм - он основал свою версию ИС на существующем польском слове ludożercy (^юдоеды) ${ }^{16}$, благодаря чему она воспринимается весьма натурально. Обратим внимание на тот факт, что по-русски

15 Толковый словарь русского языка, [в:] электронный ресурс: http://feb-web.ru/ feb/ushakov/ush-abc/25/us4d5525.htm (12.10.2015).

16 A. P o 1 k o w s k i, Kilka stów od tłumacza..., указ. соч, Poznań 2001, с. 468. 
версия „Смертееды” также звучала бы натурально, однако такой версии не находим в переводе. В общем, на этот раз М. Спивак полностью соглашается с Дж. К. Роулинг, добавляя лишь больше эмоциональности в ИС. А. Польковский полемизирует с исходным ИС на уровне формы, но полностью сохраняет изначальную семантику ИС.

На основании вышеприведенных примеров становится очевидным, насколько ИС и текст произведения, в котором они используются, тесно связаны друг с другом. В конечном итоге надо сказать, что „говорящие” имена начинают действительно говорить только тогда, когда читатель и переводчик активно углубятся в текст и попытаются найти взаимоотношения между описаниями референта ИС и самим ИС. По всей вероятности, как переводчик, так и читатель получают возможность полемизировать и акцептировать изначальные намерения писателя в вопросе наполнения ИС значением, поскольку воображение, а в том числе коннотативная цепь значений, работают у каждого человека по-разному. Что касается самих переводов ИС из саги о Гарри Поттере, то следует отметить, что семантика и форма исходных ИС отражалась в переводах неточно не только из-за культурно-языковых расхождений, но также из-за собственной творческой инвенции переводчиков. Однако независимо от того, как бы человек ни понимал ИС, они все-таки являются основным творческим приемом в процессе строения фикционального мира в литературном тексте.

\section{Библиография}

3 и м о в е ц Н.В., К вопросу о значении и переводе имени „Гарри Поттер” в романах Дж. К. Роулинг, „Вестник МГОУ. Сер. Лингвистика” 2011, № 5.

К а л и н к и н В.М., От литературной ономастики к поэтонимологии, „Логос ономастики" 2006, № 1.

К а л и н к и н В.М., Поэтика онима, Донецк 1999.

К а п к о в а С.Ю., Перевод личных имен и реалий в произведении Дж. К. Ролинг „Гарри Поттер и Тайная комната”, „Вестник ВГУ. Сер. Лингвистика и межкультурная коммуникация" 2004, № 1.

Н и к и т и н М.В., Лексическое значение слова, Москва 1983.

Толковый словарь русского языка, [в:] электронный ресурс: http://feb-web.ru/feb/ ushakov/ush-abc/25/us4d5525.htm (12.10.2015).

B e r ti $11 \mathrm{~s}$ Y., Beyond identification. Proper names in children's literature, Turku 2003.

$\mathrm{K}$ a r d e 1 a H., Onomazjologiczny aspekt semantyki kognitywnej, [в:] Język a kultura. Podstawy metodologiczne semantyki wspótczesnej, под ред. I. Nowakowskiej-Kempnej, Wrocław 1992. 
P o 1 k o w s k i A., Kilka stów od ttumacza, czyli krótki poradnik dla dociekliwych, [в:] J.K. R o w l i n g, Harry Potter i Kamień Filozoficzny, Poznań 2000.

P o 1 k o w s k i A., Kilka stów od ttumacza, czyli krótki poradnik dla dociekliwych, [в:] J.K. R o w 1 i n g, Harry Potter i Czara Ognia, Poznań 2001.

$\mathrm{S} \mathrm{t}$ a $\mathrm{n}$ d o w i c z A., Chosen aspects of the Polish translation of J.K. Rowling's "Harry Potter and the Philosopher's Stone" by Andrzej Polkowski: Translating proper names, [в:] электронный ресурс: http://translationjournal.net/journal/49potter.htm (13.10.2015). 